\title{
Mixed Mycobacterium Avium-Intracellulare and Serratia Marcescens Cellulitis of the Breast in an HIV-Negative Patient with Breast Cancer: A Case Report
}

\author{
Andreas Kyvernitakis ${ }^{1}$, Jacques Azzi ${ }^{2}$, Dimitrios P. Kontoyiannis ${ }^{1}$ \\ 1. Infectious Diseases, University of Texas MD Anderson Cancer Center 2. Internal Medicine, Staten \\ Island University Hospital
}

$\square$ Corresponding author: Jacques Azzi, azzijack@yahoo.fr

Disclosures can be found in Additional Information at the end of the article

\section{Abstract}

Mycobacterium avium-intracellulare (MAI) causes pulmonary infection in patients with chronic lung diseases or severe T-cell deficiency. Cutaneous manifestations caused by MAI are rare and the few cases reported describe mostly patients with hematologic malignancies who were treated with highly immunosuppressive agents. Herein, we report a case of a breast cancer survivor who developed chronic breast cellulitis due to MAI, following localized breast cancer treatment.

Categories: Infectious Disease, Oncology

Keywords: nontuberculous mycobacterium, breast cancer, skin infection

\section{Introduction}

Mycobacterium avium-intracellulare (MAI), the most common nontuberculous mycobacterium in the world, is an opportunistic pathogen that is notorious for causing pulmonary infections in patients with chronic lung disease and disseminated disease in patients with acquired immune deficiency syndrome [1-2]. Skin and soft tissue infection (SSTI) secondary to MAI is a rare entity in the absence of mycobacterial bloodstream infection (BSI). To our knowledge, the following report is the first description of MAI-related SSTI in a patient with a solid tumor [1, 3-6]. MAI soft tissue manifestations in patients with solid tumors have not been described before. To our knowledge, this is the first patient case reported of MAI soft tissue infection in a solid tumor. Informed consent was obtained from the patient for this study.

Received 05/17/2016 Review began 05/27/2016 Review ended 06/03/2016 Published 06/09/2016

C) Copyright 2016

Kyvernitakis et al. This is an open access article distributed under the terms of the Creative Commons Attribution License CC-BY 3.0., which permits unrestricted use, distribution, and reproduction in any medium, provided the original author and source are credited.

\section{Case Presentation}

This is a 71-year-old female who was recently diagnosed with a $1.2 \mathrm{~cm}$ left breast ductal carcinoma in situ (estrogen receptor weakly positive/progesterone receptor negative). She underwent a left segmental mastectomy with sentinel lymph node biopsy followed by adjuvant radiation therapy and placement of a catheter evacuation device. On her three-month followup visit, the patient complained of left breast tenderness, erythema, and a foul-smelling nipple discharge. Her symptoms had been ongoing for two weeks during which she also experienced intermittent low grade fevers and malaise. Physical examination was notable for a markedly tender left breast with associated erythema, induration $(11 \mathrm{~cm} \times 9 \mathrm{~cm})$, and skin thickening overlying the site of radiation. Ultrasound of the breast revealed an underlying subcutaneous seroma measuring $4 \mathrm{~cm} \times 8 \mathrm{~cm} \times 5.2 \mathrm{~cm}$. Subsequent aspiration of the cavity recovered $40 \mathrm{ml}$ of 


\section{Cureus}

purulent fluid from which Serratia marcescens was eventually isolated. Of interest, the patient had an $S$. marcescens urinary tract infection six months ago. The patient was started on a sevenday regimen of ciprofloxacin after which she continued to experience purulent nipple discharge and diffuse breast erythema. Her course was further complicated by the development of a diffuse pruritic maculopapular rash that prompted the discontinuation of ciprofloxacin.

Four weeks after the aspiration, cultures also grew MAI. At that point, there was a modest improvement of the breast cellulitis, but persistent drainage of purulent fluid (Fig. 1A). Human immunodeficiency virus (HIV) serology results were negative. She was placed on an oral combination regimen, consisted of rifabutin (300 mg/day), clarithromycin (500 mg twice/day) and doxycycline (100 mg twice/day). Doxycycline, although an unconventional agent for the treatment of $S$. marcescens, was used instead of quinolones due to the patient's recent history of hypersensitivity to ciprofloxacin, as it has in vitro activity against $S$. marcescens [7]. The patient's seroma was aspirated again, draining $10 \mathrm{ml}$ of yellow fluid that was sent for cultures and returned negative (Fig. $1 B$ ). In addition to rifabutin and clarithromycin, the patient was placed on intravenous ertapenem (1000 mg/day), followed by a course of oral cefixime (400 $\mathrm{mg} /$ day), and she received local wound care with topical silver nitrate, leading to a complete resolution of the erythema and drainage. Follow-up for the next 12 months showed progressive healing, and follow-up cultures did not grow MAI or Serratia (Fig. 1C).

A.

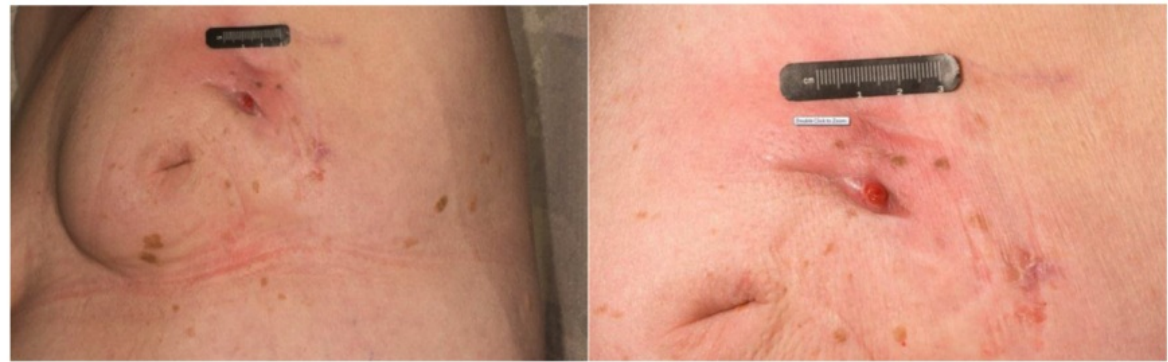

B.

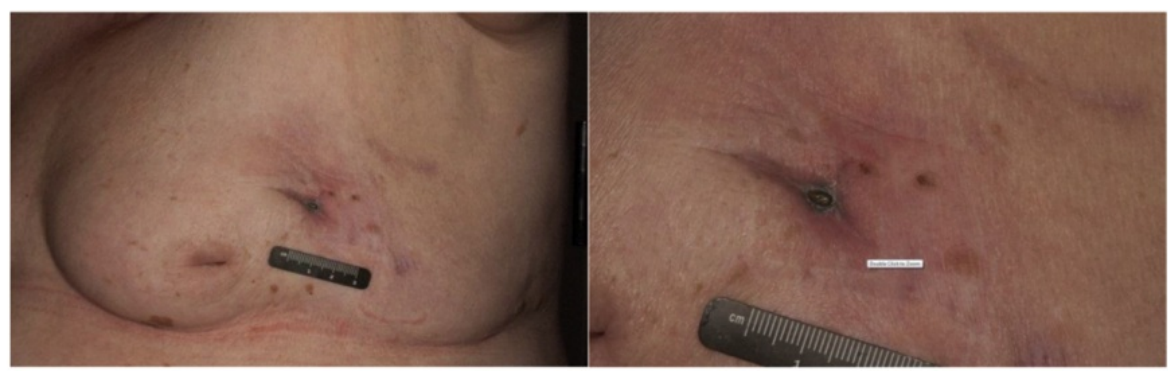

C.

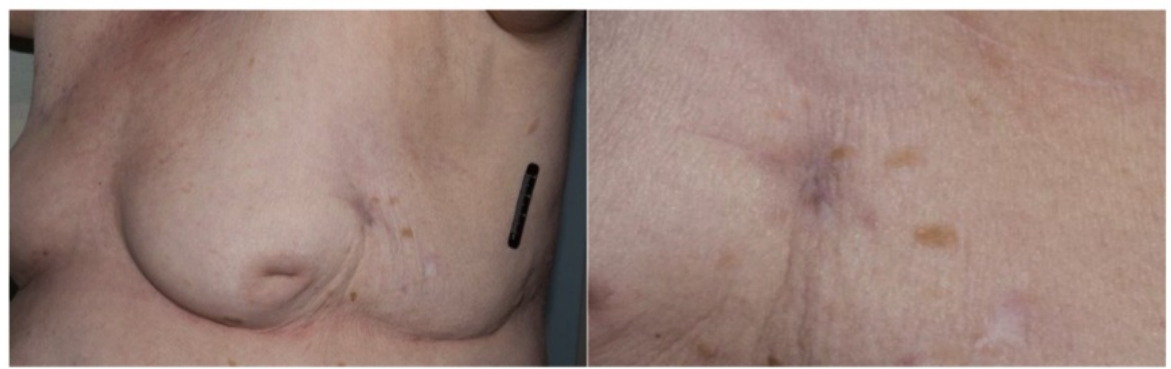

FIGURE 1: Breast seroma infected with Mycobacterium aviumintracellulare and Serratia marcescens 


\section{Discussion}

SSTIs secondary to MAI infection are thought to occur via hematogenous seeding in the context of an underlying trauma. Some of the well-established cutaneous manifestations include scaling papules, subcutaneous/ulcerative nodules, granulomatous plaques, and abscesses [3, 8]. Presumptively, in our patient, the recent breast surgery and radioadjuvant therapy served as the nidus for seeding $S$. marcescens and MAI. The few reports existing in the literature of cutaneous MAI infection in non-HIV infected cancer patients describe mostly leukemia patients who were treated with highly immunosuppressive agents $[1,6]$.

A combination of surgical debridement and a three-drug regimen with macrolides (clarithromycin or azithromycin), ethambutol, and a rifamycin (rifampin or rifabutin) may be extrapolated from studies of HIV-infected patients. [2, 9-10].

\section{Conclusions}

While an optimal treatment for an extra-pulmonary MAI infection isolated to the soft tissue has not yet been defined, a combination of surgical debridement and a three-drug regimen with macrolides, ethambutol, and rifamycin may provide a successful outcome and should be considered.

\section{Additional Information}

\section{Disclosures}

Human subjects: Consent was obtained by all participants in this study. Institutional review board at MD Anderson Cancer Center issued approval PA 14- 0829. Conflicts of interest: In compliance with the ICMJE uniform disclosure form, all authors declare the following: Payment/services info: All authors have declared that no financial support was received from any organization for the submitted work. Financial relationships: All authors have declared that they have no financial relationships at present or within the previous three years with any organizations that might have an interest in the submitted work. Other relationships: All authors have declared that there are no other relationships or activities that could appear to have influenced the submitted work.

\section{References}

1. Friedman BF, Edwards D, Kirkpatrick CH: Mycobacterium avium-intracellulare: cutaneous presentations of disseminated disease. Am J Med. 1988, 85:257-263.

2. Karakousis PC, Moore RD, Chaisson RE: Mycobacterium avium complex in patients with HIV infection in the era of highly active antiretroviral therapy. Lancet Infect Dis. 2004, 4:557-565. 10.1016/S1473-3099(04)01130-2

3. Aboutalebi A, Shen A, Katta R, Allen SE: Primary cutaneous infection by Mycobacterium avium: a case report and literature review. Cutis. 2012, 89:175-179.

4. Endly D, Ackerman L: Disseminated cutaneous mycobacterium avium complex in a person with AIDS. Dermatol Online J. 2014, 20:22616.

5. Inwald D, Nelson M, Cramp M, Francis N, Gazzard B: Cutaneous manifestations of mycobacterial infection in patients with AIDS. Br J Dermatol. 1994, 130:111-114. 10.1111/j.1365-2133.1994.tb06894.x

6. Nannini EC, Keating M, Binstock P, Samonis G, Kontoyiannis DP: Successful treatment of 


\section{Cureus}

refractory disseminated Mycobacterium avium complex infection with the addition of linezolid and mefloquine. J Infect. 2002, 44:201-203. 10.1053/jinf.2002.0970

7. Traub WH: Antibiotic susceptibility of Serratia marcescens and Serratia liquefaciens . Chemotherapy. 2000, 46:315-321. 10.1159/000007304

8. Nassar D, Ortonne N, Gregoire-Krikorian B, Roujeau JC: Chronic granulomatous Mycobacterium avium skin pseudotumour. Lancet Infect Dis. 2009, 9:136. 10.1016/S14733099(09)70023-4

9. Ward TT, Rimland D, Kauffman C, Huycke M, Evans TG, Heifets L: Randomized, open-label trial of azithromycin plus ethambutol vs. clarithromycin plus ethambutol as therapy for Mycobacterium avium complex bacteremia in patients with human immunodeficiency virus infection. Clin Infect Dis. 1998, 27:1278-1285. 10.1086/514999

10. Griffith DE, Aksamit T, Brown-Elliott BA, Catanzaro A, Daley C, Gordin F, et al.: An official ATS/IDSA statement: diagnosis, treatment, and prevention of nontuberculous mycobacterial diseases. Am J Respir Crit Care Med. 2007, 175:367-416. 